\title{
1 The Scripts of the Nag Hammadi Codices
}

The Coptic manuscripts known as the 'Nag Hammadi Codices', discovered, in 1945, in a jar in Jabal al-Tarif, near the modern-day village of Hamrah Dum in Egypt, comprise a corpus of thirteen papyrus manuscripts containing 51 texts (originally written in Greek and subsequently translated into Coptic). ${ }^{2}$ According to Stephen Emmel's calculations, this corpus consists of 'a minimum of 1,240 inscribed pages', of which ' 1,156 are currently represented by at least one fragment'. ${ }^{3}$ It was only in the 1970s that a facsimile edition of all the Nag Hammadi material, produced under the auspices of UNESCO, was completed. ${ }^{4}$

Numerous scholars have worked on distinguishing the hands of the different scribes who produced the manuscripts, among them Henri-Charles Puech, Jean Doresse, Martin Krause, Stephen Emmel, Michael Allen Willams, Aleksandr Khorsroyev and Alberto Camplani (see Table 1$).^{5}$

These scholars have taken into account the differences in scribal hands found in the manuscripts, though almost exclusively in relation to questions of language, content and codicology; much less attention, however, has been paid to the purely

1 On the discovery of the codices of Nag Hammadi, see the account (though not accepted by all Coptologists) provided by James R. Robinson in NHC 1984, with earlier bibliography; see also Robinson 2014, 399-419. The codices of Nag Hammadi (henceforth cited as NHC) presently belong to three public institutions: the Coptic Museum in Cairo (inv. nos 4851, 10544-55, 10589, 10590, 11597, 11640); the Institute for Antiquity and Christianity at Claremont Graduate University (California), which owns the binding of NHC I; the Beinecke Library at Yale University, New Haven (Connecticut), which holds the portion of a leaf of NHC III (pp. 145-146). On the origin of NHC, see Goodacre 2013, 303322; Denzey Lewis / Ariel Blount 2014, 399-419. For complete bibliography to 2006, see Scholer 1971; Scholer 1997; Scholer 2009. The place of the origin is discussed by Lundhaug / Jenott 2015. Their investigations could not be considered in detail since the outcome of this article was in 2008. In their opinion the origin of the NHC lies 'by a Christian monastic setting in Upper Egypt' (1), more precisely they see the origin as well as reception expanded and deepened in the Pachomian federation with its several monasteries (262). See also the critical review of Piwowarczyk / Wipszycka 2017.

2 As some of the 51 texts can be found more than once in the NHC, the number of original texts decreases to 45, 36 of which were previously unrecorded.

3 Emmel 1991, 1772.

4 NHC I (1977) [TM 107741]; NHC II (1974) [TM 107742]; NHC III (1976) [TM 107743]; NHC IV (1975) [TM 107744]; NHC V (1975) [TM 107745]; NHC VI (1972) [TM 107746]; NHC VII (1972) [TM 107747]; NHC VIII (1976) [TM 107748]; NHC IX-X (1977) [TM 107749-107750]; NHC XI-XII-XIII (1973) [TM 107751-107752-107753]; NHC 1979; NHC 1984.

5 See Puech 1950; Doresse 1958; Krause 1963; Krause / Labib 1971; Krause, 1975; Emmel 1978; Krause 1978; Williams 1987; Williams 1992; Williams 1995; Khorsroyev 1995, 136-142; Williams 1996, 235-262; Camplani 1997. 
graphical aspect of the manuscripts. This lack of attention can be explained by the very limited degree of palaeographical research into Coptic scripts; what research has been done has been conditioned by a theoretical approach which oscillates between two extremes: on the one hand, the wholesale acceptance of the findings of Greek palaeography and on the other the uncompromising rejection of these findings, which can lead to a form of palaeographical scepticism so extreme as to deny the possibility of even a hypothetical dating of the manuscripts. In effect, the Coptic bookhands have not been-or only very rarely and partially-the subject of comprehensive monographic studies which can shed light on their specific characteristics and the similarities and differences with Greek scripts. ${ }^{6}$ The preference of scholars has often been to study single scribal products or groups of them-such as the Nag Hammadi codices-producing careful detailed descriptions of all the material features but paying little attention to an analysis of the writing. If we look for example at the palaeographical terminology which has been employed to described the varieties of script found in the thirteen Coptic manuscripts, it is impossible not to recognise that the linguistic imprecision of the descriptions conceals problems which are in essence theoretical: 'regular, upright uncial' or 'upright capital script often with ligature' to describe the main scribal hand in NHC II;' 'casual, flowing uncial script' for NHC III; 'handsome regular uncial script' for NHC IV;' 'handsome, flowing uncial script' for NHC VII; 'Thick-and-thin style' for NHC VIII; 'round uncial, with cursive feature' for NHC IX; '12 'primitive version of the Biblical majuscule type' for $\mathrm{NHC} \mathrm{i}^{13}$ 'formal mixed hand of a sloping kind' for the first scribal hand found in NHC XI and 'formal round majuscule, more round than the Biblical majuscule' for the second scribal hand contained in it; ; 'Biblical Majuscule' for NHC XII; 'regular, uncrowded Biblical majuscule without embellishment (e.g. serifs)' for NHC XIII. ${ }^{16}$

6 For studies in Coptic codicology and palaeography, see Layton 1985; Emmel 1993; Emmel 1999; Boud'hors 2006; for a particularly important study, see Boud'hors 1997. On Coptic Biblical majuscule, see Orsini 2008a and the Coptic Biblical Majuscule chapter in this volume. For an interesting study on the relation between Greek and Coptic scripts in fourth-century manuscripts, see Gardner / Choat 2004.

7 Waldstein / Wisse 1995, 4.

8 Böhlig / Wisse 1975, 2.

9 Böhlig / Wisse 1975, 2.

10 Pearson 1996, 5.

11 Sieber 1991, 5.

12 Pearson 1981, 8-10.

13 Pearson 1981, 218-219.

14 Hedrick 1990, 4, 7-10.

15 Hedrick 1990, 292.

16 Hedrick 1990, 362-363. 
There are too many definitions, frequently imprecise, referring to the same typologies of script. The scripts found in the Nag Hammadi manuscripts refer to only a few general models, which can be listed as follows: 1. unimodular Alexandrian majuscule (preceding the script's canonical phase, described by Guglielmo Cavallo as 'the Alexandrian stylistic class'; 2. Biblical majuscule; 3. a mixture of features from Alexandrian majuscule and Biblical majuscule; 4. a script occupying a transitional position between the 'severe style' and sloping pointed majuscule.

The present study, therefore, aims to provide a comparative analysis of these graphic typologies, with the principal aim of placing them in the context of the history of Greek-Coptic scripts. Such a procedure must of course be based on drawing accurate distinctions between the scribal hands found in the corpus and as a result identifying groups of hands on purely stylistic grounds.

\subsection{Scripts based on Alexandrian majuscule}

The largest group of codices contain hands which take as their model unimodular Alexandrian majuscule, or rather the phase of the scripts which Guglielmo Cavallo has called 'the Alexandrian stylistic class', that is to say, a class of scripts in which the characteristic features of the style have not yet become canonical (a development which would only occur between the end of the fourth and beginning of the fifth centuries CE). ${ }^{17}$ The axis of the script is vertical; rounded forms and curved strokes are preferred; the loops are accentuated, whereas the terminal shadings are little developed. The following forms of certain letters should be noticed: the alpha is looped, drawn in a single stroke without lifting the pen but there are also examples written in two pen strokes (with the oblique stroke descending from left to right traced as a round bow); delta and lambda at times show the upper part of the oblique stroke from left to right (slightly curved) ending in a small curl; epsilon is written in three strokes, with the upper bow at times closing on the horizontal stroke; $m u$ is written in a single pen stroke but also in two or three, with all the strokes concave; upsilon is written with both one and two strokes, in the shape of a 'horn' with a loop at the base; phi is written with a round or rhomboidal bowl, but contained within the bilinear space; omega is written with one or two strokes, with a central loop; gima tends to be fitted in within the bilinear space. Although there are

17 Irigoin 1959a; Cavallo 1975; Cavallo 1977a, 109-110; Porro 1985; Cavallo 2005; Cavallo 2008, 101-105; Radiciotti 2008; Cavallo 2009, 129-131; Bastianini / Cavallo 2011; Crisci / Degni 2011, 120-123. For dated or datable manuscripts in Alexandrian majuscule, see Orsini / Clarysse 2012, 453 n. 41. 
differing levels of execution, the scripts found in NHC III, IV, V, VI, VIII, and IX belong to this class and can be dated to the first half of the fourth century, as we will see in greater detail, on the basis of comparison with P. Lond. VI 1920 (330-340 CE; TM 44659) ${ }^{18}$ and P. Lond. Copt. 522 (fourth century; TM 107974) ${ }^{19}$ for NHC III, and P. Ryl. III 489 + P. Lond. inv. 2852 (first half of fourth century; TM 61453) ${ }^{20}$ for the remaining manuscripts in this group.

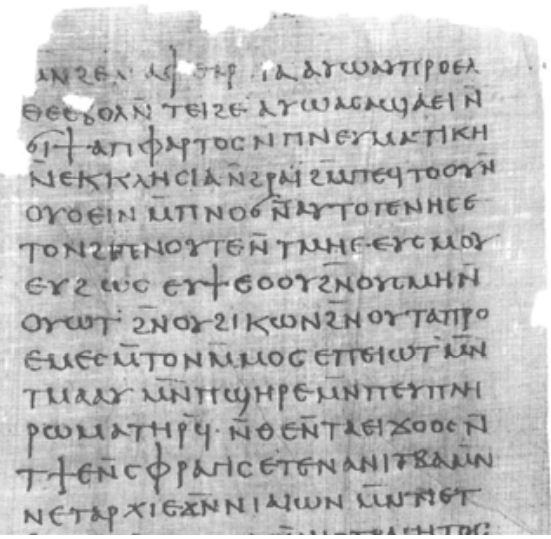

Fig. 1: NHC III, 55.

The majuscule present in NHC III, ${ }^{21}$ written by a single scribe, is executed rather roughly, placed irregularly on the base line and displays evident lack of modular uniformity (Fig. 1). While the scribe's taste for round forms and loops is obvious, the terminal shadings are only slightly accentuated. In delta and lambda the upper part of the oblique stroke descending from left to right is not looped; epsilon, written with three strokes, is angular in form; omega is written either with a single stroke of the pen (with a central loop) or with two strokes (the initial bow followed by the vertical middle stroke joined to the second bow); hori is in the form of the figure ' 2 '; gima has a small lobe while the upper bow ends in an elongated flourish within the bilinear space.

18 Cavallo / Maehler 1987, 22, 24 and pl. 8a.

19 Crum 1905, 251-252, no. 522, pl. 10. The palaeographical comparison was suggested by Khorsroyev 1995, 142 n. 411.

20 P. Ryl. III, pl. 10; Cavallo / Maehler 1987, 22, 25 and pl. 8b.

21 NHC III (1976); Wisse 1975, 232; Böhlig / Wisse 1975, 2; Waldstein / Wisse 1995, 2. For the colophon at p. 69, ll. 6-17, see Bellet 1978. 
The single scribe who wrote NHC IV ${ }^{22}$ was clearly inclined to use round forms and loops (Fig. 2). Compared with the writing in NHC III, the execution here is more careful; there are fewer modular irregularities while the script is more regularly placed on the base line. The overall axis of the writing leans slightly to the left while a contrast can be noted between thin strokes (horizontal and oblique ascending left to right) and thick strokes (vertical). The oblique stroke descending from left to right in delta occasionally shows a small loop at the upper tip; epsilon is formed of three strokes, with a horizontal stroke extending to the right beyond the body of the letter while the upper bow tends to close on the horizontal stroke; $m u$ is written in one stroke with prominent loops and only on rare occasions in four strokes (see examples at p. 24, 1. 28); upsilon is looped and in the form of a 'horn' but when coming at the end of a line examples can be found of the letter written in three strokes and descending below the base line; the tail of shai descends below the base line almost vertically, with an end flourish to the left; fai has a small upper bow.

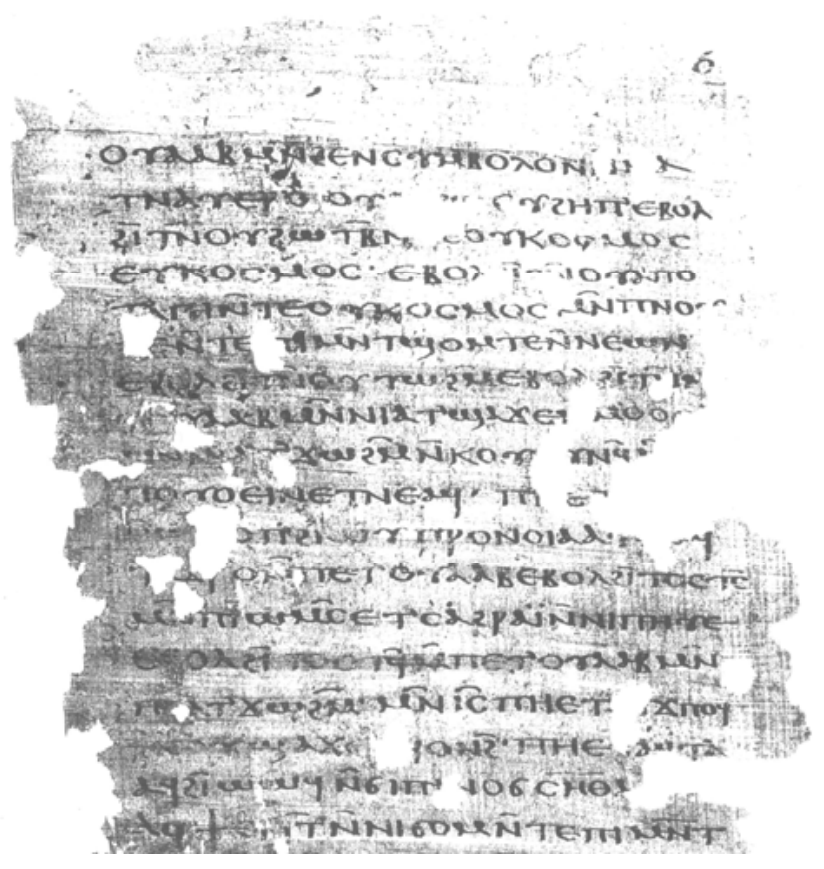

Fig. 2: NHC IV, 75.

22 NHC IV (1975); Böhlig / Wisse 1975, 9; Waldstein / Wisse 1995, 5; Camplani 1997. 


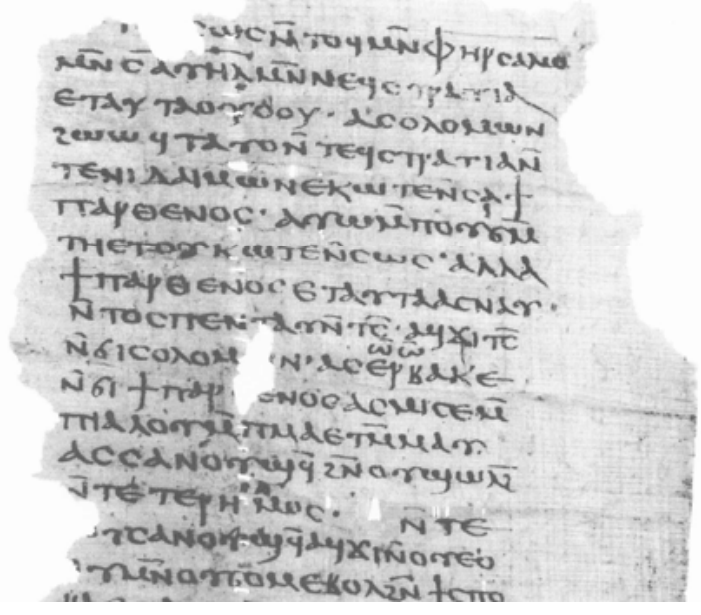

Fig. 3: NHC V, 79.

NHC $\mathrm{V}^{23}$ is also written by a single hand and again shows a taste for round forms and loops (Fig. 3). The alignment on the base line, however, is irregular, like the module of the individual letters. The direction of the script is on occasion slightly sloping to the left and the distinction between thick and thin strokes is heavier and less controlled than we find in NHC IV. It is noteworthy that some vertical strokes which descend below the base line (rho, phi, psi, fai, ti) have a small serif turned to the left. The oblique stroke descending from left to right in delta is sometimes straight and sometimes curved; epsilon is written in three strokes, with the horizontal stroke extending beyond the body of the letter; in kappa the two oblique strokes are either straight or slightly curved, while the upper stroke presents a slight terminal shading; the bowl of rho is small; the horizontal stroke of tau has small ornamental flourishes at either end; upsilon is looped and in the form of a 'horn', with the curved strokes at time extended to touch the base line; however, we can also find, though more rarely, a form of upsilon written in three strokes with the oblique lines curved and the vertical line extending below the base line; the upper curve of fai is small. Compared with NHC IV, the quality of the writing is undoubtedly inferior and there are many differences in the structure of the letters. We can therefore

23 NHC V (1975); Doresse 1958, 164-167; Krause / Labib 1971, 26; Manfredi in Robinson 1975, 18; Parrott 1979, 1-2. 
exclude the possibility that the same scribe was responsible for NHC IV and V, although they certainly share general characteristics and as a result can be attributed to the same period.

The hand found in $\mathrm{NHC} \mathrm{VI}^{24}$ differs from those found in the codices just described (Fig. 4). The execution is fairly crude and the alignment on the base line is irregular and hesitating. The writing is slightly sloping to the left and the module of the letters is compressed on the base line. As far as the contrast between thick and thin strokes is concerned, the vertical strokes are thickest while the horizontal strokes and the oblique strokes ascending from left to right are thinnest, while all the other strokes vary from minimal thinness to average thickness (see, for example, $n u)$. Also in this codex we find that the strokes of certain letters which descend below the base line (rho, phi, psi, fai, ti) have a small serif turned to the left, although this is less consistently done than we find in NHC V. Epsilon is written in three strokes, with a small serif at the end of the upper curve and the horizontal stroke extended beyond the body of the letter; the oblique strokes of kappa are slightly curved; the oblique stroke of $n u$ is on occasion undulated; the horizontal stroke of tau has small ornamental flourishes at either end; upsilon is looped and in the form of a 'horn', with curved strokes developing; the upper bow of fai is small.

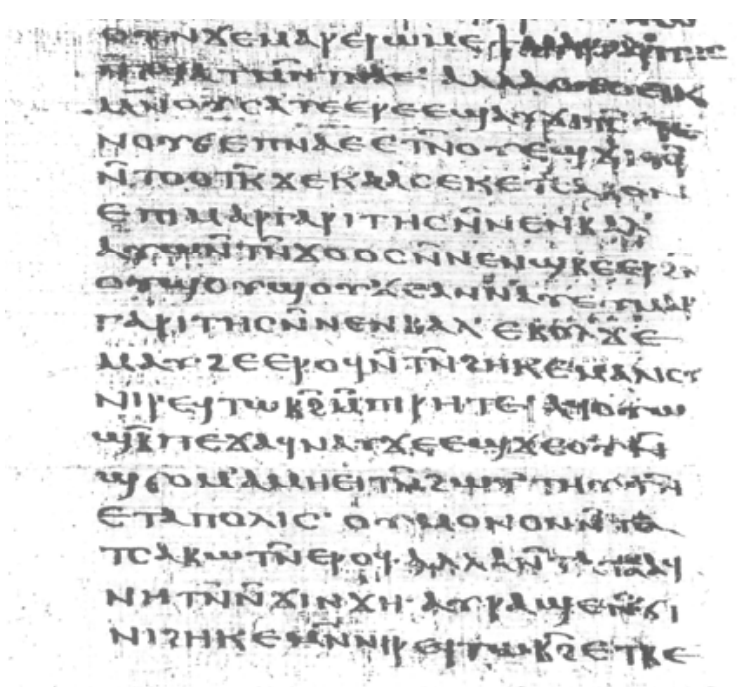

Fig. 4: NHC VI, 4.

24 NHC VI (1972); Camplani 1997; Crisci 2004, 135-136. 


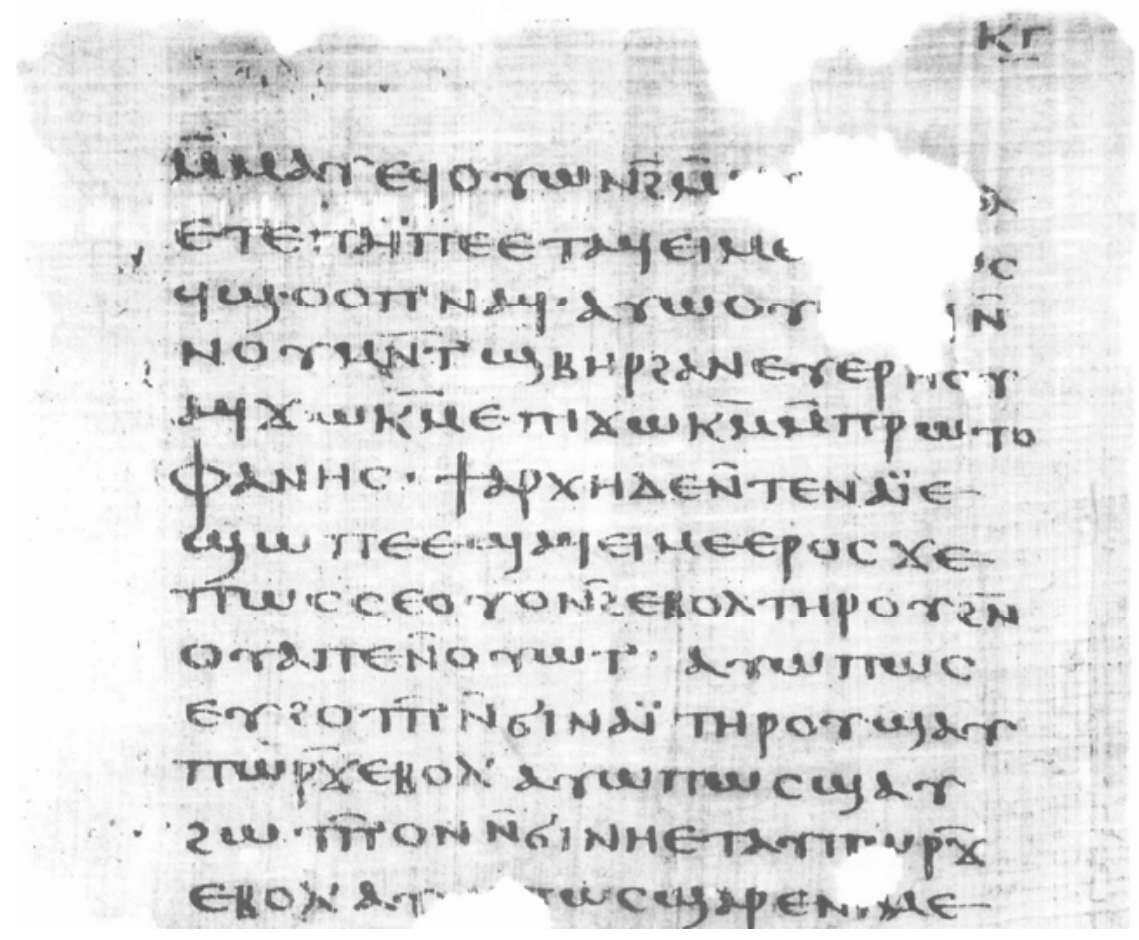

Fig. 5: NHC VIII, 23.

Another hand again is found in $\mathrm{NHC} \mathrm{VIII}^{25}$ (Fig. 5). The writing is upright, though it slopes to the left on occasion. The contrast between thick and thin lines is careful and on the whole consistent; vertical strokes are the thickest, while horizontal and oblique strokes ascending from left to right are thinnest, and the oblique strokes descending from left to right are of medium thickness (varying on occasion between maximum and medium thickness). In delta and lambda the upper part of the oblique stroke descending from left to right is accentuated; epsilon is written in three strokes, on occasion with an angular appearance to the curve of the letter; the oblique strokes of kappa are slightly curved and show shaded tips; the tail of shai is somewhat vertical, ending in a flourish to the left.

25 NHC VIII (1976); Sieber 1991, 4; Krause / Labib 1971, 6. 
In NHC IX,,$^{26}$ the work of a single scribe, at times the vertical strokes which descend below the base line end with a small serif turned to the left (Fig. 6). The axis of the writing is vertical although there is occasional minor sloping to the left. The distinction between thick and thin strokes is accentuated, but the thickness of some strokes (especially the oblique ones) is irregular. The scribe has a liking for loops and rounded forms. The oblique stroke descending from left to right in delta and lambda is slightly curved and the upper part is extended; in kappa the oblique strokes are slightly arched.

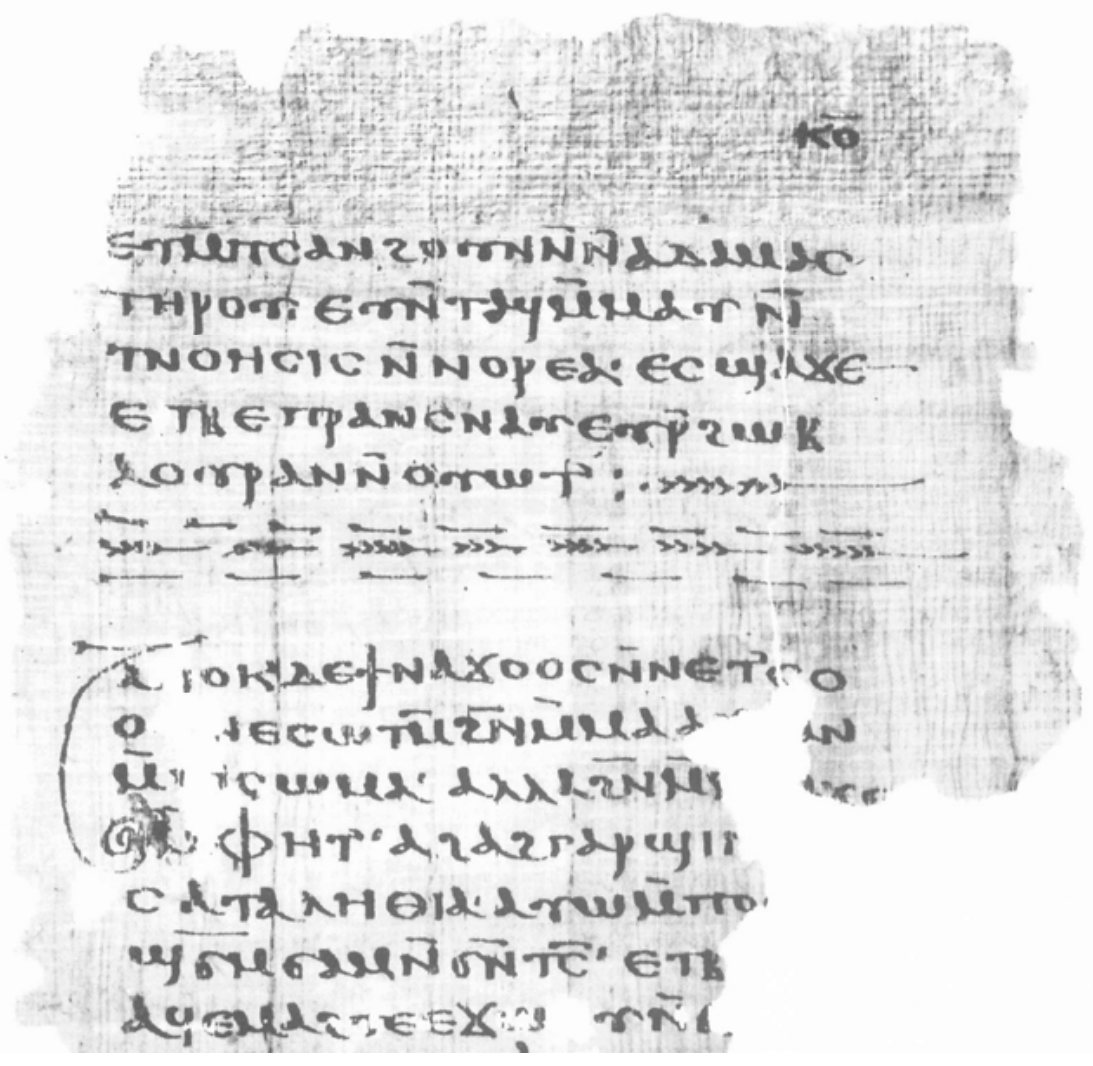

Fig. 6: NHC IX, 29.

26 NHC IX-X (1977); Pearson 1981, 1-18; Doresse 1958, 164-167; Krause 1963, 110; Krause / Labib 1971, 6, 8; Emmel 1978, 28; Manfredi in Robinson 1975, 18; Crisci 2004, 135-136. 


\subsection{Scribal styles based on Biblical majuscule}

Writing styles based on Biblical majuscule can be found in NHC I (pp. A-43, 1. 24; 51-138), NHC II (both hands: the first on pp. 1-46, 47, 1. 8-145; the second in the first eight lines of p. 47), NHC X, NHC XII, which displays the features characteristic of the beginning of the 'period of decline of the canonical style': ${ }^{27}$ the writing angle is frequently irregular, largely because of its poor quality, which causes the oblique strokes from left to right to vary from medium to maximum thickness, with minimal thickness found only at times in $n u$; terminal shading is rarely found in thin strokes; alpha is formed either of three or of two strokes, with the oblique stroke from left to right at times slightly extended below the base line; the oblique stroke of $n u$ is at times slightly curved; rho and epsilon extend slightly below the base line. References for comparison are P. Oxy. XVII 2101 (second half of fourth century; LDAB 4205) for NHC I (pp. A43, 1. 24; 51-138), P. Berol. inv. 5011 (BKT 8 15) (second half of fourth century; LDAB 3266) for both hands found in NHC II, and P. Oxy. XIII 1600 (end of fourth century; LDAB 2609) for NHC X and XII.

The first hand found in NHC I (pp. A-43, 1. 24; 51-138) ${ }^{28}$ varies noticeably in size, is badly aligned on the base line and the writing angle is somewhat irregular (Fig. 7). The thickness of the strokes is irregular and inconsistent: only the horizontal lines are consistently of a minimal thickness, while the oblique strokes show notable variations. The bilinear system is continually infringed by letters varying in size, sometimes small and sometimes large. Alpha is written in three strokes, with an oblique middle stroke while the stroke descending from left to right sometimes extends below the base line; beta, written in four strokes, shows two detached small bowls; the stroke of kappa from left to right ends with a small left-facing hook; $m u$ is written in four strokes with the second oblique stroke slightly extended below the base line, beyond the point of contact with the first oblique stroke; in $n u$ the middle stroke is curved; epsilon, theta and omicron are frequently enlarged in comparison with the other letters; rho has a small bowl; both ends of the vertical stroke in tau show on occasion some slight ornamental shading; the stroke descending from left to right of upsilon is sometimes straight and sometimes curved; it should also be noted that its size

27 Cavallo 1967a, 64-76; Orsini 2005a, 179-185; for the history of Biblical majuscule, see also Cavallo 1977a, 106-107; Cavallo 2008, 98-101; Cavallo 2009, 128-129; Crisci / Degni 2011, 106111. For Coptic Biblical Majuscule, see Orsini 2008a and the Coptic Biblical Majuscule chapter in this volume. For dated and datable manuscripts in Biblical majuscule, see Orsini / Clarysse 2012, 452 n. 37.

28 NHC I (1977). 
usually breaks the bilinear system both above and below; the bowl of phi is contained within the two lines while the left half is rounder than the right one; hori is written in two strokes and the lower part is angular. While this writing style shows the influence of Biblical majuscule, it cannot be said to belong entirely to the 'canon'.

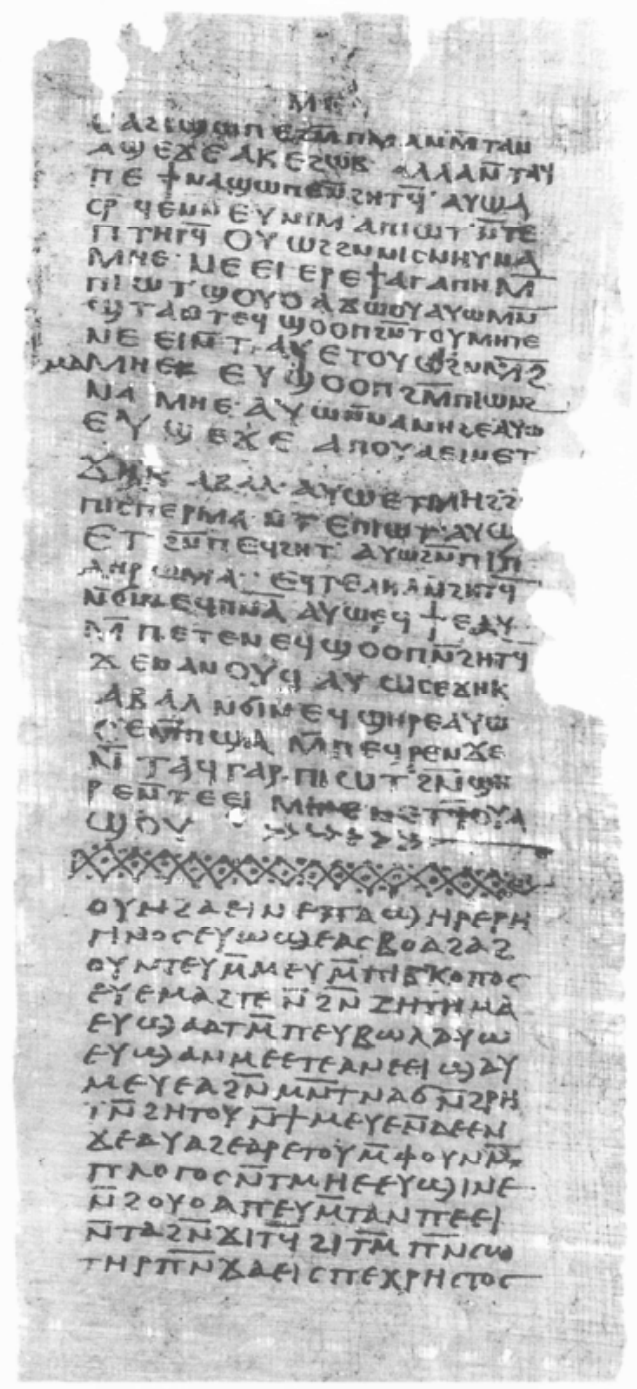

Fig. 7: NHC I, 43. 


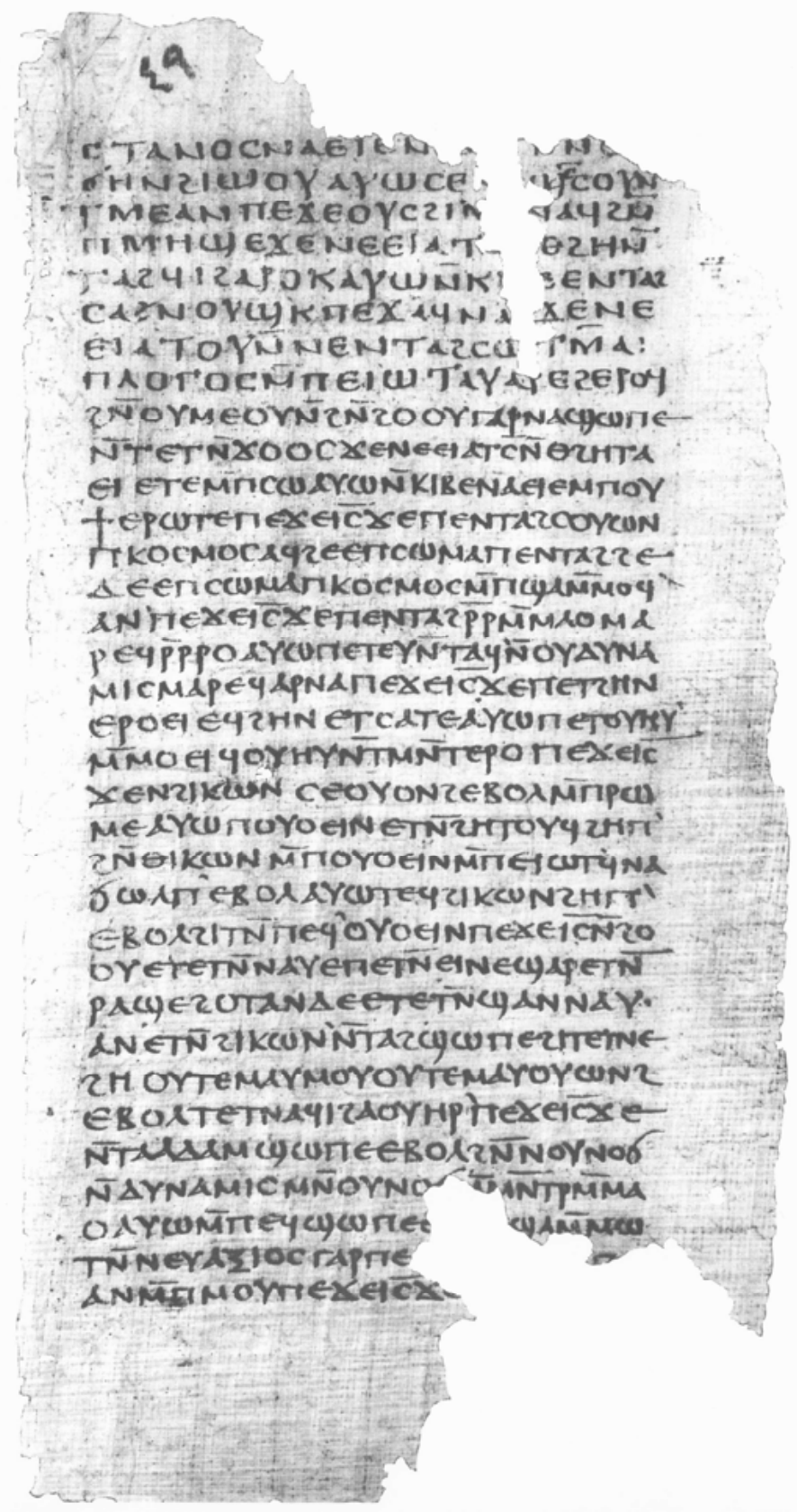

Fig. 8: NHC II, 47. 
Two hands in succession can be found in $\mathrm{NHC} \mathrm{II}^{29}$ (the first on pp. 1-46 and 47, 1. 8-145; the second only in the first eight lines of p. 47) (Fig. 8). The main hand writes in a somewhat rough style, although the writing angle is fairly regular (see for example the oblique strokes descending from left to right of medium thickness, in $n u$ as well). Terminal shadings are rarely found, only in the ends of the horizontal stroke of tau and at the top ends of the descending oblique stroke of alpha, delta and lambda. In alpha and lambda the oblique stroke descending from left to right is curved; beta is written sometimes in four strokes and sometimes in three (with the two bowls traced in a continuous stroke); epsilon has an upper loop that often closes on itself while the horizontal stroke extends beyond the body of the letter; the horizontal stroke of eta is raised above the centre; the oblique strokes of kappa do not start from the centre of the vertical stroke but slightly below it; in $m u$ the oblique strokes tend to be written without lifting the pen from the paper, with the result they are curved rather than angled; the bowl of phi is round and contained in the space between the lines; in shai the stroke extending below the base line is almost vertical and ends in a left-turned serif; the body of gima is round and enlarged, and looks similar to omicron. ${ }^{30}$

The hand that wrote the first eight lines on p. 47 appears less expert than the first, judging from the uncertain alignment on the base line, the irregularity in the module of the letters, and the more artificially contrived angle of the writing. ${ }^{31}$ There is a larger presence of ornamental flourishes at the ends of certain thin strokes (very clearly seen in the ends of the horizontal stroke of tau); epsilon has a round body and a terminal shading to the middle stroke; the middle stroke of eta is slightly raised; in kappa the lower oblique stroke terminates with a small serif to the left; $m u$ is written in four strokes and the stroke descending from left to right is of medium thickness; the oblique stroke of $n u$ is of minimal thickness and is curved; the bowl of rho is very small; the vertical strokes of rho and upsilon extend slightly below the base line.

The single scribe who penned NHC $\mathrm{X}^{32}$ is also working in the area of influence of Biblical majuscule, although many features of individual letters differ

29 NHC II (1974); Layton 1989, 4-5.

30 According to Layton 1976, 84, it would seem that this hand also copied NHC XIII; see also Layton 1989, 4; Layton 1974, 357-358; Waldstein / Wisse 1995, 4; Giversen 1963, 34-40; Camplani 1997, 128; Crisci 2004, 135 n. 97: 'even though the two hands (the first hand in NHC II and that in NHC XIII) are undoubtedly very similar, it seems to me that there are differences which lead one to suppose there were two scribes'.

31 According to Crisci 2004, 135, 'the scribe of MS. X, or at least a different scribe with similar graphic training, also wrote MS. II, f. 47, 11. 1-8'.

32 NHC IX-X (1977); Krause / Labib 1971, 9; Pearson 1981, 211-227; Crisci 2004, 135. 
markedly from the 'canon' (Fig. 9). The writing angle is irregular; the oblique strokes descending from left to right vary from maximum to medium thickness. Small ornamental serifs are found at the ends of thin strokes. Alpha is written in three and also in two strokes, with a horizontal serif on the top of the stroke descending from left to right (also found in delta and lambda) while the bottom end has a short horizontal tail towards the right; beta is written in four strokes; the back of epsilon and sigma is fairly stiff; in kappa the upper oblique stroke is very thin and terminates with a hook to the left; in $n u$ the oblique stroke is curved; rho extends slightly below the base line; upsilon sometimes has the stroke descending from left to right straight and sometimes wavy, and extends slightly below the base line; omega has flattened curves; gima has a round bowl and the upper stroke extends upwards.

\section{CIANETEMANTOYCAHI MIMEY NETKHRAECTX EIAMAT TEECENCMHIT MAYUERKE: NAACYAE CECATTIANHARON: EIENIN̈ TOYCMHINAR NETCN TMHTEAENA" FOYOAAMAXI ETOY TC" CEQEH D.J AT CAY METRADOYOY MAMNTAEANET TEET OAXE KATAE! NTONOAMOCIAN̄N ? TEMNNNATREAOC' PEYTEZTUR ANO}

Fig. 9: NHC X, 27. 


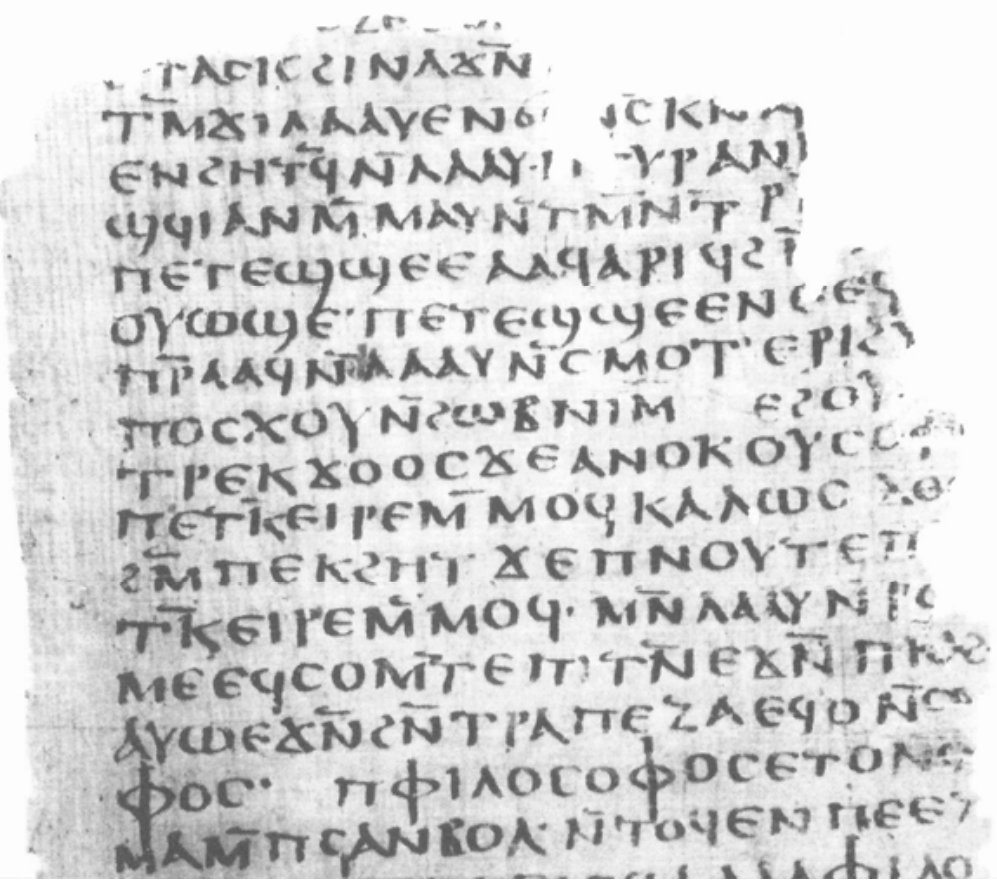

Fig. 10: NHC XII, 34.

The writing angle in NHC XII ${ }^{33}$ is irregular: the strokes descending from left to right vary from medium to maximum thickness (Fig. 10). Alpha is sometimes in three strokes and sometimes in two, and the oblique stroke descending from left to right occasionally extends below the base line; beta is written in four strokes; in delta and lambda the oblique stroke descending from left to right extends upwards; $m u$ is in four strokes, except for certain looped forms which only appear at the end of lines; rho extends slightly below the base line; the vertical stroke of tau has serifs at either end; upsilon has the leftwards oblique stroke sometimes straight and sometimes wavy; the bowl of phi is roundish and contained within the bilinear space.

33 NHC XI-XII-XIII (1973); Krause / Labib 1971, 13; Hedrick 1990, 289-294. 


\subsection{Combination of characteristics from Alexandrian majuscule and Biblical majuscule}

Two scribes use hands which combine features from two different styles, Alexandrian majuscule and Biblical majuscule. The first was responsible for the whole of NHC VII ${ }^{34}$ and pp. $45-72$ of NHC XI, ${ }^{35}$ while the second copyist wrote NHC XIII. ${ }^{36}$

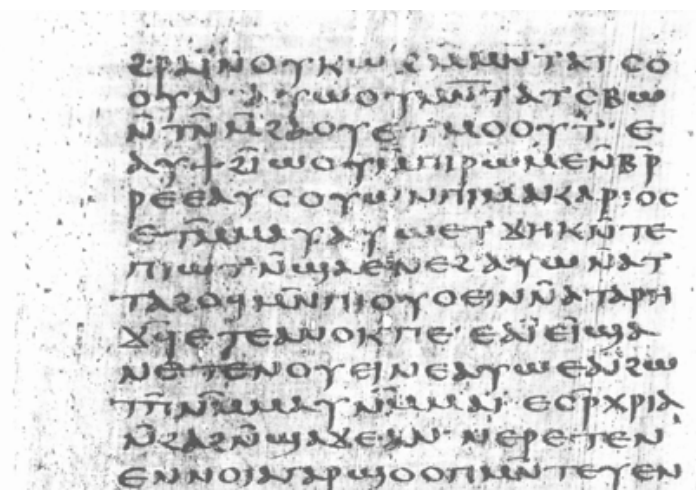

Fig. 11: NHC VII, 59.

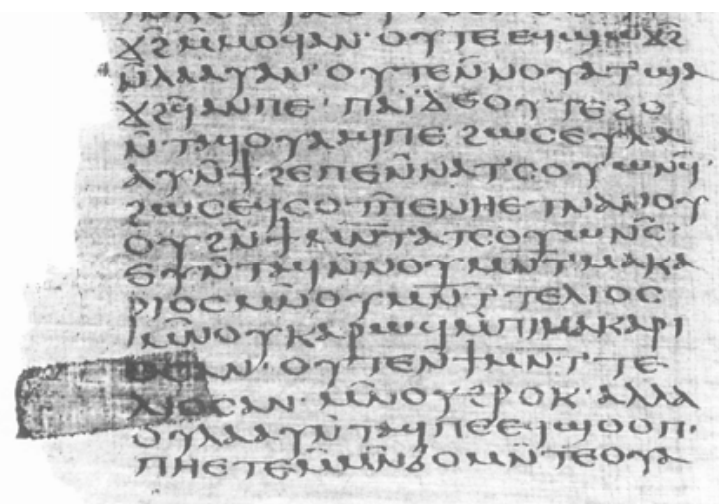

Fig. 12: NHC XI, 65.

34 NHC VII (1972); Krause / Labib 1971, 3; Pearson 1997, 44-61; Pearson 1996, 1-13.

35 NHC XI-XII-XIII (1973); Hedrick 1990, 3-20; Camplani 1997; Crisci 2004, 136.

36 NHC XI-XII-XIII (1973); Krause / Labib 1971, 14; Emmel 1978, 27-28; Hedrick 1990, 359369; Crisci 2004, 135. 
The first scribe (Fig. 11-12) shows a taste for round forms and loops reflecting the influence of Alexandrian majuscule; on the other hand, he employs an accentuated contrast of thick and thin strokes and certain characteristics of the letters relate to Biblical majuscule. The strokes descending from left to right in alpha, delta and lambda extend upwards breaking the bilinear space; their thickness varies from medium to maximum. The strokes that descend below the base line (rho, upsilon, phi, psi, fai, ti) sometimes slope obliquely to the left and sometimes terminate in a progressively thinning stroke. Small ornamental flourishes are found at the end of thin strokes. Alpha is looped and in two strokes; beta is written in four strokes and has two round bowls; epsilon is written in three strokes, with the horizontal stroke raised; kappa has the two oblique strokes slightly curved, and the upper one ends with a terminal shading; $m u$ is both looped and written in three strokes, with a wide central curve; in $n u$ the oblique stroke is curved and has an average thickness, though there are also examples where this stroke gets progressively thinner; in $p i$ the two vertical strokes are slightly curved and splayed outwards; upsilon is in three strokes with heavily curved oblique strokes (though there are also examples where these strokes are perfectly straight) and the vertical stroke descends below the base line; the loop of phi is in the form of a rhomboid and is contained within the bilinear space; hori, shaped as a ' 2 ', is in two strokes, with the lower one undulating; gima, in the form of a ' 6 ', has a rigid oblique stroke (ending with a terminal shading) and a small round bowl.

The scribal hand found in NHC XIII (Fig. 13) has a vertical axis and the contrast of thick and thin is typical of Biblical majuscule (written at an irregular angle). It uses loops and roundnesses which are characteristic of Alexandrian majuscule. Alpha is written in two or three strokes, with the oblique stroke descending from left to right curved and with terminal shading at the top end; beta is written in four strokes; in delta and lambda the oblique stroke descending from left to right is arched and with terminal shading at the top end; epsilon has the horizontal stroke raised and extending beyond the body of the letter; $m u$ is looped; rho has a small loop and the vertical stroke extends slightly below the base line; upsilon is written in three strokes and tends not to go below the base line; the bowl of phi is round and contained within the bilinear space; omega occasionally has a central loop; gima has a round bowl, and the terminal stroke is extended upwards. ${ }^{37}$

37 A correction found in NHC II, 12, 1. 18 has been linked to the hand that wrote NHC XIII (see Turner 1990, 362). It is in fact very difficult to establish whether it is the same scribe: the correc- 


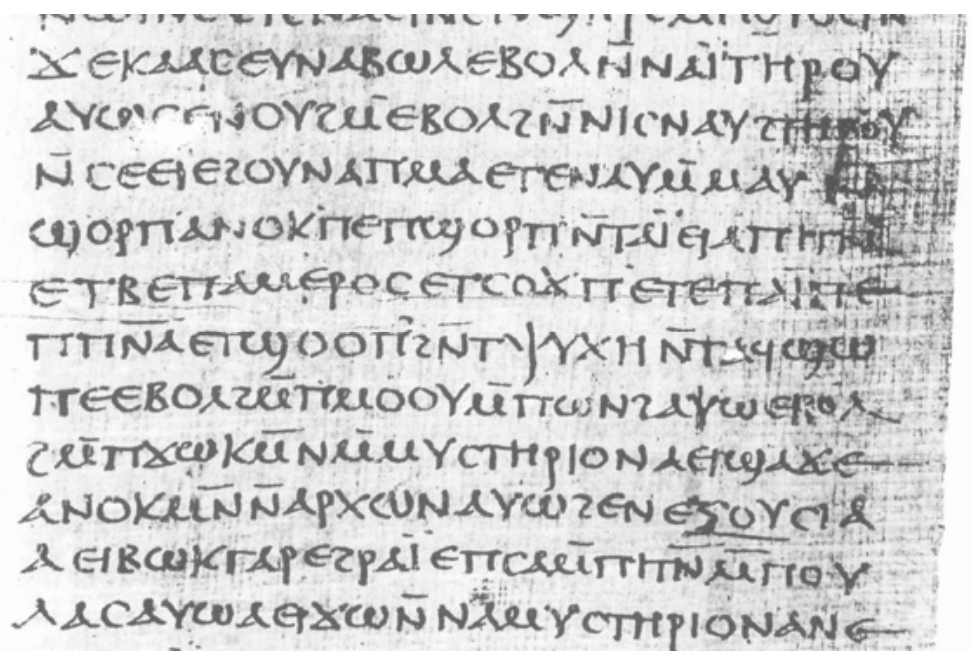

Fig. 13: NHC XIII, 41.

It is interesting to see that attempts at writing in this style, a mixture of elements taken from Alexandrian majuscule and Biblical majuscule, are rarely found in Greek manuscripts while they are frequently found in Coptic production. It is a phenomenon found in Egypt, to be more precise in the Greek-Coptic ambience and is a fusion, sometimes more pronounced and sometimes less so, of the two Greek writing styles.

\subsection{Transition from severe style to sloping pointed majuscule}

The same scribe wrote the middle part of NHC I (pp. 43, 1.25-50, 1.18 [the rest of the page is blank] ${ }^{38}$ and the initial part of NHC XI (pp. 1-44), ${ }^{39}$ employing a style which reflects the transition between severe style with a sloping axis to sloping pointed majuscule (Fig. 14-15). ${ }^{40}$ Besides the right-leaning slope of the writing,

tion is written in a cursive hand sloping to the right; the strokes of the single letters are traced differently from those found in the script of NHC XIII.

38 NHC I (1977).

39 NHC XI-XII-XIII (1973); Hedrick 1990, 3-20; Camplani 1997.

40 On the 'severe style', see Schubart 1925, 124-132; Turner 1987, 26; Funghi / Messeri 1989; Del Corso 2006; Cavallo 2008, 105-111; Cavallo 2009, 131-132; Crisci / Degni 2011, 73-74. For some dated and datable manuscripts in 'severe style', see Orsini / Clarysse 2012, 456 n. 54 . It is 


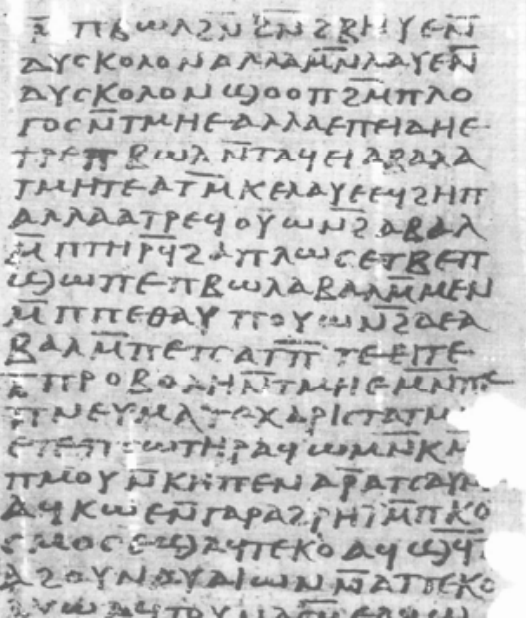

Fig. 14: NHC I, 45.

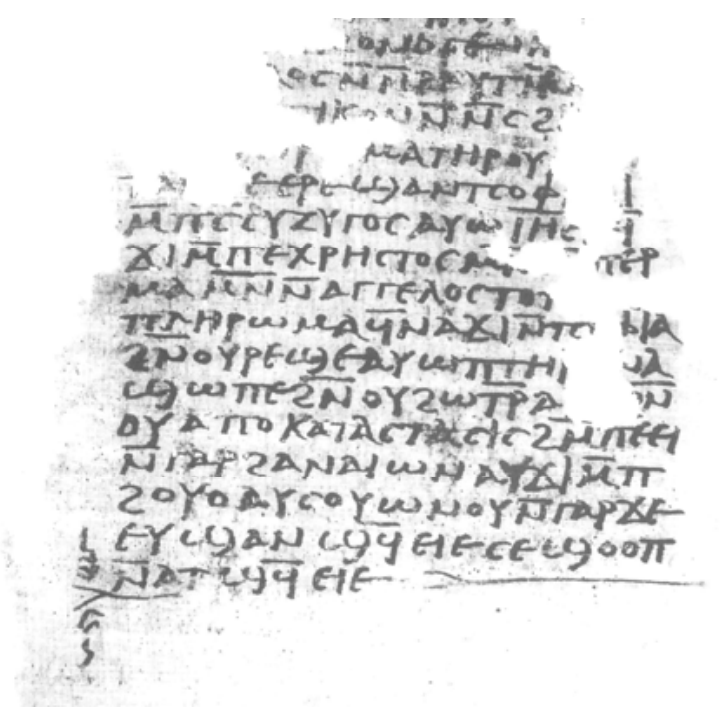

Fig. 15: NHC XI, 39.

also worth mentioning Sandre 1977, who correctly identified this scribe in the two Nag Hammadi manuscripts, but proposed an improbable dating in the end of the second century. 
other features include an irregular lineation along the base line, contrasting sizes, and unemphatic shading. In alpha, delta and lambda the stroke descending from left to right is undulated and often extends both upwards and downwards; alpha is written in two or three strokes; beta has the two bowls detached, with the lower one more angular than the upper one; the middle stroke of epsilon extends beyond the body of the letter; theta extends the horizontal stroke only to the right, to the point where it touches the following letters; the lower oblique stroke of kappa is arched and at times extends below the base line; $m u$ has a wide central curve and the second vertical stroke is curved; the oblique stroke of $m u$ is undulating; the loop of rho is angular; in shai the tail, which extends below the base line, is continuous together with the terminal stroke of the right curve; in hori the lower curve is broken and angular; the body of janja is enlarged. Parallels for this style of writing can be found in P. Berol. $10566+10558+10559^{41}$ (attributable to the end of the fourth century; LDAB 5596); in P. Bodmer XXI + P. Chester Beatty Ac. 1389 (datable to the fifth century; LDAB 108537); in P. Beatty XII (datable to the fourth century; LDAB 2608). These parallels would therefore support an attribution of date to the end of the fourth century.

\subsection{Results of the investigation}

The results of the palaeographical analysis have been summarised in two tables: in the first (Table 1) the different hypotheses, including those advanced in the present study, on the distinction of hands are shown; in the second (Table 2) the different graphic typologies and the relative attributions of date are shown for the individual scribes.

As far as the distinction between different scribes is concerned, the account given here confirms the hypotheses proposed by Stephen Emmel and Michael Allen Williams, although there are differences above all in how the graphic and stylistic characteristics of the hands are grouped. Emmel does not exclude the possibility of identifying scribes 1 and 14 as the same person, despite the fact that they belong to different graphic typologies, and the quality of execution and treatment of single letters also differs between the two. Williams-who was the first scholar to point out the considerable graphic differences between the scribes of NHC IV, V, VI, VIII and IX-suggests plausibly that scribes 6 and 10, as well as 7, 8, 11 may be grouped together on palaeographical grounds, but he underestimates the importance of the stylistic aspect when he hypothetically

41 Schubart 1911, pl. 43. 
suggests that scribes 3 and 14 are the same person. The first writes in a mixture of Biblical majuscule and Alexandrian majuscule, whereas the second uses a Biblical majuscule, albeit crudely executed.

As far as the chronological sequence is concerned, the proposals made here on the basis of graphic and stylistic characteristics range from the beginning to the end of the fourth century, and as such do not vary from the conclusions of earlier studies. It is of interest, however, to connect these datings with certain palaeographical features.

The graphic typologies found (Table 2) and the differing qualities of execution reveal these scribes to have been working wholly within Greek-Coptic scribal culture, even though particular features are present which enable us to distinguish between specifically Greek and Coptic ambiences. The 'Alexandrian stylistic class' found in the NHC echoes for the most part the mature graphic features found in Greek manuscripts of the period although one feature stands out which distinguishes its use from the Greek ambience: the alternation, not always consistent, of thin strokes (horizontal and oblique ascending from left to right) with thick strokes (vertical), and the variation from minimum to maximum thickness in the oblique strokes descending from left to right. These features are not found in Greek manuscripts of this period. Guglielmo Cavallo has said that in the Greek ambience ' $t$ t]he chiaroscural effects of thick and thin strokes are caused [...] not so much by the angle of the pen (in any case the letters are written with a more or less rigid pointed calamus, not capable of creating a marked contrast between thick and thin strokes) but rather by the bending and overlapping of lines in the play of loops and the deliberate insertion of shading, ${ }^{42}$

In actual fact, the terminal shadings are absent in the Alexandrian class found in the NHC and perhaps their absence can be explained by the treatment of the thick and thin strokes mentioned above: the distinctive ornamental function of the terminal shadings has been replaced by the chiaroscural alternation of thick and thin strokes. Both a wider and more focussed investigation into this phenomenon in Coptic scribal culture, hitherto unattempted, could identify the truly distinctive elements in this script in its various historical phases and help us to separate out the features which emerge from innovative practices in relation to Greek scribal culture.

The Biblical majuscule found in the NHC follows the chronological phases of the corresponding writing style in the Greek-speaking world, though it should be pointed out that the quality of execution is fairly low. This confirms

42 Cavallo 1975, 30. 
the findings of a specific investigation on Coptic Biblical majuscule: ${ }^{43}$ the general development of this writing in Coptic-speaking areas appears to follow the same general tendencies and chronological stages we find in Greek-speaking areas, at least over the course of the fifth century until the early sixth century. From about the first half of the sixth century we begin to see signs of a special, more independent interpretation of this style of writing in Coptic areas.

Composite writing styles, which combine Alexandrian and Biblical majuscules, are of great interest. Jean Irigoin referred many years ago in his essay on Alexandrian majuscule ${ }^{44}$ to a group of Greek and Coptic manuscripts attributed to the fifth and sixth centuries (for example P. Vindob. K 15, TM 61745, Vat. Borg. Copto 109/65, LDAB 2898, P. Vindob. G 19802, LDAB 3049, P. Berol. 13994, LDAB 3310) in a composite writing style which can be seen as representing the emergent phase of a 'canonical' Alexandrian majuscule as this developed from an ulterior form of Biblical majuscule. Guglielmo Cavallo on the other hand, in suggesting that the origins of Alexandrian majuscule can be reconstructed on the basis of second-century manuscripts, ${ }^{45}$ regarded these 'hybrid forms' as a product of the influence of the ultimate bookhand, as the fifth- and sixthcentury Biblical majuscule undeniably was, on a writing style which was 'still generically calligraphic': '[...] it represents a compromise between forms that belong to the writing styles generally found in the fifth and sixth centuries, and which scribes tend to practise spontaneously, and the modalities and characteristics of a style such as Biblical majuscule which, while no longer current, still had the weight of Christian tradition and doctrine behind it and was therefore an inevitable model for scribal imitation' ${ }^{46}$

However, what emerges from the present study of the NHC is that, in reality, a distinction needs to be drawn between these composite writing styles: there are manuscripts in which Alexandrian majuscule shows the influence of Biblical majuscule and there are others in which the contrary is found. These are different phenomena: the basic graphic style is either Alexandrian or Biblical majuscule onto which stylistic features or certain forms of pen-stroke execution have been grafted. Those graphic styles which are still substantially Alexandrian employ a contrasting chiaroscuro which is characteristic of Biblical majuscule, while in those which follow the overall graphic structure of Biblical majuscule certain letters with typical Alexandrian majuscule forms (alpha, mu,

43 See the Coptic Biblical Majuscule chapter in this volume.

44 Irigoin 1959a, 41-44.

45 Cavallo 1967a, 113-117; Cavallo 1975.

46 Cavallo 1967a, 117. 
upsilon) have been introduced. Examples of the first class include the fifth- or sixth-century fragment of Qasr Ibrim containing the Gospel of Saint Mark (Cairo, Coptic Museum, inv. $6569+6570+6571$; LDAB 2912), ${ }^{47}$ the sixth-century fragment of St Paul's Second Letter to the Corinthians (P. Vindob. G 19802; ${ }^{48}$ LDAB 3049), and the sixth-century fragment of Exodus (P. Berol. 13994; ${ }^{49}$ LDAB 3310); while for the second-in addition to early testimonies such as the Heraclides Ponticus (P. Oxy. IV 664 + P. Oxy. L 3544; LDAB 1091), attributable to the early third century, ${ }^{50}$ and Julius Africanus, Kestoi (P. Oxy. III 412; LDAB 2550), mid third century, ${ }^{51}$ in which elements pertaining to two different graphic canons coexist-one should mention scribes $\mathrm{E}$ and $\mathrm{F}$ in the Codex Visionum (P. Bodmer XXIX + XXX-XXXVII + XXXVIII; LDAB 1106), attributable to the fourth or fifth century, ${ }^{52}$ and the fragment of Psalms (P. Mich. III 132; LDAB 3243), datable to the fifth century. ${ }^{53}$

This second class enjoyed more success: as early as the third and fourth centuries there are examples, albeit only a handful, of its use in both the Greek and Coptic-speaking areas, while from the fifth century onwards in the Coptic world it started to become a writing style in the proper sense of the term, described by Viktor Stegemann as the 'dicker Stil ${ }^{54}$ and by other modern Coptic scholars as the

47 Plumley / Roberts 1976, including pls 1-2; Crisci 1996, 119-121, pl. XCVIII.

48 Cavallo / Maehler 1987, 84-85 and pl. 38a; Schefzyk 2006, 117 no. 50.

49 BKT 8, pl. 2; Cavallo 1967a, pl. 103 b; Cavallo / Maehler 1987, 84-85 and pl. 38b. Guglielmo Cavallo and Herwig Maehler refer to the script of the last two fragments as an 'hybrid script', which they believe was used for writing Coptic and bilingual Greek-Coptic texts.

50 P. Oxy. L, pl. XI; Orsini 2005a, 91-93. The text was probably written by a single scribe, despite the discernible presence of small variations in the writing of some letters: within a writing system based on a Biblical majuscule, attributable to the beginning of the third century, we find letters such as $m u$ written in concave strokes, all concave, and upsilon written in two strokes and shaped as a Latin $V$ or in three strokes, the third short and vertical at the basis, occasionally substituted by a thick stroke.

51 P. Oxy. III, pl. V. Its script can be assigned to the Biblical majuscule canon, with $m u$ written in three concave strokes, and upsilon in the shape of a 'horn': see Crisci 2005, 111, pl. 4.

52 The division of hands considered here follows the distinction proposed by Cavallo in P. Bodmer XXXVIII, 116-124. See also P. Bodmer XXIX, 99-117; P. Bodmer XXX-XXXVII, 5-7; Crisci 2004, 115-122, pls 1-4. These two hands used a Biblical majuscule reintroducing alpha and $m u$ in Alexandrian style.

53 In the graphic structure of Biblical majuscule, looped alpha and $m u$ in three strokes, with a large central bow, were introduced.

54 Stegemann 1936, 14. It is worth noting that Stegemann's ‘dicke[r] Typus des Bibelstils' or, in more general terms, 'dicker Stil' refer to a second 'phase' of Biblical majuscule beginning from the fifth and sixth centuries. He also extended the same description to include a graphic style that combined elements of Biblical majuscule with Alexandrian majuscule (see Stegemann 
'thick-and-thin style'. ${ }^{55}$ This can clearly be seen in such manuscripts as Lond. Orient. MS 9035 (13) (fifth century; LDAB 108459); ${ }^{56}$ hands A and C in Wash. Freer Copt. 1 (late fifth century; LDAB 107936); ${ }^{57}$ New York, Pierpont Morgan Library, 664 A (4), ff. 1-2 + Paris. Copte 1297 , f. 35 + Copte 128 $8^{8}$, ff. 121-122, 140, 157 + Copte $129^{9}$, ff. 49, 65, $76+$ Copte $120^{10}$, f. $209+$ Copte $132^{2}$, f. 60 + Vat. Borg. Copt. 109, cass. VII, fasc. 65, ff. 1-21 (fifth-sixth century; LDAB 2898); ${ }^{58}$ Lond. Orient. MS 14149 (13-27) (fifth-sixth century; LDAB 108310)..$^{59}$ Yet it is also clear that this 'compromesso tra forme', to use Cavallo's expression, ${ }^{60}$ can be documented as early as the third and fourth centuries and is not only characteristic of the general writing styles in the fifth and sixth centuries. The Nag Hammadi codices, together with the other Greek manuscripts we have cited, enable us to document the early phase of a phenomenon which subsequently developed in various ways and which, above all for Coptic, gave rise to a distinct writing style which I propose should be called the 'mixed style'. ${ }^{61}$

One aspect of the Nag Hammadi codices which has been much discussed relates to the documents found as waste in the bindings of the codices. For a long time these have been used as elements with which to date the manuscripts in the

1936, pls 10.2, 15.2, 17). From a scientific point of view, in fact, 'dicker Stil' cannot be used to describe both late Biblical majuscule and one other writing style that does not belong to the canon of Biblical majuscule, simply because the two scripts share an artificially exaggerated chiaroscuro effect. These styles present different letter strokes and forms and, consequently, they must be considered as distinct scripts. Indeed, the mixed style script is more correctly described as '[...] mixed types of script that are a kind of compromise between Biblical majuscule and Alexandrian majuscule' in Kasser 1991f, 177.

55 It would also be worth reassessing the expression 'thick-and-thin style' frequently used by modern Coptologists to describe writing 'in which vertical strokes are thick and horizontal strokes are thin. The style is common especially in scripts with wide epsilon, omicron, sigma, and is characteristic of e.g. the great Biblical uncial style' (Layton 1987, LXIV). As a result, the expression 'thick-and-thin style' is used in Layton's catalogue to describe Biblical majuscule (e.g. no. 8, pl. 1.2), the mixed style (e.g. no. 23, pl. 2.2), and also Alexandrian majuscule influenced by Biblical majuscule in the structure of its letters, the latter described by Layton as 'tending towards thick-and-thin style' (e.g. no. 11, pl. 1.7).

56 Layton 1987, 42, no. 39, pl. 9.3.

57 Worrell 1923, XV-XVIII, 1-106, pls I-IV: Worrell identified three hands (A, pp. 18-104, 1. 3 a, 116-117, 126-237, 248-252; B, pp. 104, 1. 3 b-115, 118-125, 238-247; C, pp. 253-258), although he advances the doubtful conjecture that 'the whole manuscript is from one hand' (Worrell 1923, XVI); Biblia Coptica 1.4 (2000), sa 116, pl. 6.

58 Follieri 1969, 13-14, pl. 4; Biblia Coptica 3.1 (2001), 504, pl. 2.

59 Biblia Coptica 3.1 (2001), 510, pl. 4.

60 Cavallo 1967a, 117.

61 This style is not to be mistaken for Turner’s 'Formal Mixed': see Turner 1987, 26. 
volumes in which they have been found. ${ }^{62}$ In actual fact there are only a few such documents with a more or less explicit date. From the binding of NHC V come the two Greek documents P. Nag Hamm. 22 (official accounts; TM 15621) ${ }^{63}$ and 23 (fragments from accounts; TM 32388), ${ }^{64}$ both of which were written at the time

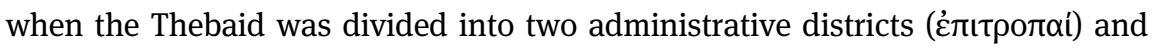
can therefore be dated to the period between 298 and 323 CE. Several Greek fragments, on the other hand, have been found in the binding of NHC VII: P. Nag Hamm. 62 (a sale contract; TM 30162), ${ }^{65}$ which might have been drawn up under the consulship of Domitius Zenofilus (333 CE) or Tettius Facundus (336 CE), although the periods of the reign of Aurelian or the rebel Domitius Domitianus or the consulate of Flavius Domitius Leontinus (344 CE) are also possible alternatives; P. Nag Hamm. 63 (loan of wheat; TM 15622) ${ }^{66}$ is dated 20 November 341; P. Nag Hamm. 64 (loan of wheat; TM15623) ${ }^{67}$ is dated 21 November 346; P. Nag Hamm. 65 (act of guarantee; TM 15624) ${ }^{68}$ is dated 7 October $348 .{ }^{69}$ If these dates are compared with the hypothetical dating for the manuscript texts, then in the case of NHC V the documents in the binding indicate a period between 298 and 313 CE and the text itself can be dated to the first half of the fourth century; for NHC VII the documents in the binding indicate a period between 333 and $348 \mathrm{CE}$ and the text itself can be dated to the second half of the fourth century. ${ }^{70}$ Both cases show a broadly chronological coherence, with periods of time from a couple of decades to a half century separating the documents used in the bindings and the texts themselves.

Yet, following the work of Ewa Wipszycka, ${ }^{71}$ it should be pointed out that the bindings of the NHC do not conform much to our idea of a binding, being more like loose covers or jackets which could be used for various codices. As a result, the link between the bindings and the work they contain need not be as close as we thought: the bindings were not necessarily made in the same place and at the

62 See the edition of Greek and Coptic documents in P. NagHamm.

63 P. NagHamm., 25-30.

64 P. NagHamm., 30-33.

65 P. NagHamm., 52-53.

66 P. NagHamm., 53-56.

67 P. NagHamm., 56-57.

68 P. NagHamm., 57-58.

69 Internal textual elements suggest a date between the death of Origen (254 CE) and the Council of Nicaea (325 CE) for the composition of the text in NHC VII: see Peel 1996, 272-274.

70 Given the relationship between scribe 9 and scribes 1 and 2, what is stated here for NHC VII is also valid for NHC I and XI.

71 Wipszycka 2000. 
same time as the production of the codices. ${ }^{72}$ Furthermore, the fragments of documents which have been extracted from the cartonnage of these bindings could have come from deposits of waste paper acquired in bulk by merchants; this might explain the mix of different types of documents (tax documents, letters, private papers) which have nothing to do with each other but which are sometimes used in the same binding. One possible explanation for the presence of letters from monks among this material is that they made the cartonnage themselves using material bought in from a seller of waste paper together with their own documents which were no longer useful. In Wipszycka's view, however, another hypothesis is possible: the documents of the monks may have come into the hands of the craftsman commissioned to prepare the bindings, who had also acquired the waste paper from a dealer. In other words, the monks were selling documents they no longer needed to a dealer in waste paper. Such a hypothesis would weaken even further the idea that there is a direct connection between the NHC and a monastic ambience. ${ }^{73}$ It is evident that the hypothesis that a waste paper dealer was involved 'demands caution in all reasoning concerning the date of when the covers were made on the basis of the dates mentioned in the documents from the papyrus stuffing, ${ }^{74}$ The bindings could have been made later than the composition of the texts they contain.

Finally, we must deal with the question of those cases where there is a change of scribal hand within a codex. In NHC I up to line 24 on page 43 scribe 1 finishes tract I, 3 (The Gospel of Truth); from line 25 onwards (after an ornamental line drawn in ink) the second hand, scribe 2 (the same hand we find in NHC XI, pp. 144), takes over to write a new text (I, 4 Treatise on the Resurrection). This scribe writes until line 8 of p. 50 where the rest of the page is left blank, and the first scribe starts a new text (I, 5 The Tripartite Tractate) at the top of the following page. Pp. 43-44, like pp. 50-51, form part of the first gathering of NHC I. ${ }^{75}$

In NHC XI scribe 2 wrote up to p. 44 (the same scribe who wrote NHC I, pp. 43, 1. 25-p. 50, 1. 18) while from p. 45 onwards scribe 9 takes over (the same scribe who wrote NHC VII). There is also a new text: on p. 44 tract XI, 2e (On the Eucharist E) begins and ends and from p. 45 tract XI, 3 (Allogenes) begins. At the end of XI, 2e there is a coronis and a small space left blank.

In these two codices the change of hand coincides with a change in text. Furthermore, the transitions are marked graphically (an ornamental line, a

\footnotetext{
72 See also Lundhaug / Jenott 2015, 126-127, 139.

73 See also Lundhaug / Jenott 2015.

74 Wipszycka 2000, 190.

75 NHC 1984, 41.
} 
coronis), by agraphon or by a change in page. This leads one to suppose that there was a planned division of the work and means that NHC I, VII and XI and scribes 1, 2, 9 are closely connected. From a graphic point of view, the three scribes are very interesting: they adopt styles of writing which imitate Biblical majuscule, the transition between severe style and sloping pointed majuscule, as well as a mixture of Alexandrian majuscule and Biblical majuscule. If the three scribes were part of a scriptorium then it was one which was capable of employing different writing styles.

In NHC II the scribe who wrote the first eight lines on p. 47 (scribe 4) has continued the same text (II, 2 The Gospel of Thomas) written by the main scribe (scribe 3) without any break. This brief intervention does not allow us to form any hypothesis on the nature of the collaboration between the two scribes: what is clear is that scribe 4 is less expert than scribe 3, even though he attempts to apply the rules of the Biblical majuscule canon more closely, suggesting that his intervention was an attempt to imitate, almost as if he was practising.

As far as the codicological aspect is concerned (Table 3), taking into consideration the main material features (type of gathering, dimensions, size and proportion) all the $\mathrm{NH}$ codices are largely uniform. Almost all consist of a single gathering, except for NHC I, which is made up of three irregular gatherings. ${ }^{76}$ As for the size $(\mathrm{W}+\mathrm{H})$ this varies between $365 \mathrm{~mm}$ and $465 \mathrm{~mm}$, in other words completely within the parameters of average size. ${ }^{77}$ The proportions of the pages $(\mathrm{W} / \mathrm{H})$ vary between 0.47 and 0.73 with a clear preference for narrow proportions, in line with the rest of Greek and Coptic papyrus production. ${ }^{78}$

In conclusion we can say that the palaeographical and codicological features of the NHC show that the production of this group of manuscripts was planned and carried out in a largely uniform way.

76 Krause 1962, 123-124; NHC I (1977), XVII, XXI, XXV; Turner 1977, 60. On the gatherings of NHC XIII, see NHC XI-XII-XIII (1973), XV, XVII; Turner 1990, 359-360; Turner 1977, 60.

77 Bozzolo / Ornato 1980, 217-220 (small size up to $320 \mathrm{~mm}$; medium-small size between 320 and $490 \mathrm{~mm}$; large size over $490 \mathrm{~mm}$ ); Maniaci 2002, 85 (small size up to $250 \mathrm{~mm}$; medium size between 250 and $500 \mathrm{~mm}$; large size over $500 \mathrm{~mm}$ ).

78 For Greek manuscripts, see Maniaci 2002, 132-133. 


\subsection{Tables}

\begin{tabular}{|c|c|c|c|c|c|c|c|c|}
\hline NHC & Puech & Doresse $^{79}$ & Krause & Emmel $^{80}$ & Williams & Khorsroyev ${ }^{81}$ & Camplani & Orsini \\
\hline I & $\begin{array}{l}\text { 1: pp. } \\
\text { A-43, } \\
\text { I. 24; } \\
51- \\
138 ; \\
2: \text { pp. } \\
43, \text { l. } \\
25- \\
50, \text { l. } \\
18\end{array}$ & $\begin{array}{l}\text { 1: pp. A- } \\
\text { 43, I. 24; } \\
\text { 51-138; } \\
\text { 2: pp. 43, } \\
\text { I. } 25-50 \\
\text { I. } 18\end{array}$ & $\begin{array}{l}\text { 1: pp. } \\
\text { A-43, l. } \\
\text { 24; } 51 \\
-138 \\
\text { 2: pp. } \\
\text { 43, l. } \\
\text { 25-50, } \\
\text { l. } 18\end{array}$ & $\begin{array}{l}\text { 1: pp. A } \\
-43, \mathrm{l} . \\
24 ; 51- \\
\text { 138; } \\
2: \text { pp. } \\
\text { 43, l. } \\
25-50, \mathrm{l} . \\
18\end{array}$ & $\begin{array}{l}\text { 1: pp. A- } \\
\text { 43, I. 24; } \\
\text { 51-138; } \\
\text { 2: pp. 43, } \\
\text { I. } 25-50 \\
\text { I. } 18\end{array}$ & $\begin{array}{l}\text { 1: pp. A-43, } \\
\text { I. } 24 ; 51- \\
\text { 138; } \\
\text { 2: pp. } 43, \text { I. } \\
\text { 25-50, I. } 18\end{array}$ & $\begin{array}{l}\text { 1: pp. A- } \\
\text { 43, I. 24; } \\
\text { 51-138; } \\
\text { 2: pp. 43, } \\
\text { I. } 25-50 \\
\text { I. } 18\end{array}$ & $\begin{array}{l}\text { 1: pp. A } \\
-43, \text { l. } \\
24 ; 51- \\
138 ; \\
2: \text { pp. } \\
43 \text {, l. } \\
25-50 \text {, } \\
\text { I. } 18\end{array}$ \\
\hline II & 3 & 3 & 3 & $\begin{array}{l}\text { 3: pp. 1- } \\
\text { 46; 47, l. } \\
\text { 8-145; } \\
\text { 4: p. 47, } \\
\text { Il. } 1-8\end{array}$ & $\begin{array}{l}\text { 3: pp. 1- } \\
\text { 46; 47, l. } \\
\text { 8-145; } \\
\text { 4: p. 47, } \\
\text { Il. } 1-8\end{array}$ & $\begin{array}{l}\text { 3: pp. 1-46; } \\
\text { 47, I. } 8-145 \\
\text { 4: p. } 47, \text { ll. } \\
1-8\end{array}$ & 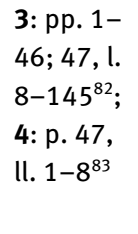 & $\begin{array}{l}\text { 3: pp. } \\
\text { 1-46; } \\
\text { 47, l. 8- } \\
\text { 145; } \\
\text { 4: p. 47, } \\
\text { Il. } 1-8\end{array}$ \\
\hline III & 4 & 4 & 4 & 5 & 5 & 5 & 4 & 5 \\
\hline IV & 5 & 5 & 5 & 6 & 6 & 6 & $5^{84}$ & 6 \\
\hline V & 5 & 5 & 5 & 7 & 7 & 6 & 6 & 7 \\
\hline VI & 5 & 5 & 5 & 8 & 8 & 7 & 7 & 8 \\
\hline
\end{tabular}

79 Doresse 1958, 164-167, according to whom 'palaeography evidence is [...] the most infallible criterion for the dating of our manuscripts' (162), grouped the hands in 4 different strands of graphical style: 'A. A cursive script, flexible and without pretention [NHC III-IX]; B. calligraphic script, rigid, with emphasised thick strokes [NHC II, XI-XIII]; C. script in which the letters are rigid, thick, and end with terminal thickenings [NHC I, XI]; D. sloping script, artificially written, having in some sense the function of italic [NHC I, XI]'.

80 According to Emmel 1978, 27-28, scribes 1 and 14 are identifiable as a single copyist, scribes 4 and 13 write in very similar hands, and the writing styles of scribes 6, 7, 8, 10 and 11 are very close, perhaps because they were all educated in the same writing school.

81 Regarding NHC IV, V, VI, VIII and IX, Khorsroyev 1995, 20-22, 142, states that they are probably not copied from more than two scribes; manuscripts NHC X and NHC II (p. 47, 1l. 1-8) 'might possibly show evidence of the same scriptorium: two (?) scribal hands' (142).

82 Camplani 1997, 128: 'in NH II and NH XIII the same scribe's hand is recognisable'.

83 Camplani 1997, 128, believes that the style of scribe 4 is 'very close' to NHC X.

84 Camplani 1997, 129-130, agrees that NHC IV, V, VI, VIII and IX emerge 'from the same school and probably the same scriptorium'; furthermore, he proposes the following groups: 'VI and IX on the one hand, perhaps copied by the same scribe, IV and VIII on the other, and V in an intermediate position'. 


\begin{tabular}{|c|c|c|c|c|c|c|c|c|}
\hline NHC & Puech & Doresse $^{79}$ & Krause & $\mathrm{Emmel}^{80}$ & Williams & Khorsroyev ${ }^{81}$ & Camplani & Orsini \\
\hline VII & 6 & 6 & 6 & 9 & 9 & 8 & 8 & 9 \\
\hline VIII & 5 & 5 & 5 & 10 & 10 & 6 & 5 & 10 \\
\hline IX & 5 & 5 & 5 & 11 & 11 & 7 & 7 & 11 \\
\hline$x$ & 1 & 1 & 1 & 12 & 12 & 9 & $9^{85}$ & 12 \\
\hline$X I$ & $\begin{array}{l}\text { 2: pp. } \\
1-44 \\
6: p p . \\
45-72\end{array}$ & $\begin{array}{l}\text { 2: pp. 1- } \\
44 \\
7: p p . \\
45-72\end{array}$ & $\begin{array}{l}2: p p . \\
1-44 \\
6: p p . \\
45-72\end{array}$ & $\begin{array}{l}\text { 2: pp. 1- } \\
44 \\
\text { 9: pp. } \\
45-72\end{array}$ & $\begin{array}{l}\text { 2: pp. 1- } \\
44 \\
9: p p . \\
45-72\end{array}$ & $\begin{array}{l}\text { 2: pp. } 1-44 \\
\text { 8: pp. } 45-72\end{array}$ & $\begin{array}{l}\text { 2: pp. 1- } \\
44 \\
\text { 8: pp. 45- } \\
72\end{array}$ & $\begin{array}{l}\text { 2: pp. } \\
\text { 1-44 } \\
\text { 9: pp. } \\
\text { 45-72 }\end{array}$ \\
\hline XII & $7^{86}$ & 8 & 7 & 13 & 13 & 10 & 10 & 13 \\
\hline XIII & 8 & 9 & $8^{87}$ & 14 & 14 & 3 & 3 & 14 \\
\hline
\end{tabular}

Tab. 1: Hands division in $\mathrm{NHC}^{88}$

85 Camplani 1997, 129: 'NH X [...] can be related to NH II f. 47 ll. 1-8, that is to say, to the style of the same scribe who collaborated with the scribe who wrote NH II and NH XIII. Perhaps the scribe of NH X belonged to this scriptorium, either coinciding with the scribe of NH II f. 47 ll. 18 , or belonging to the same school'.

86 Puech 1950, 110: 'the script of this is similar to that in our category III [= NHC II]'.

87 Krause 1963, 110-111, believes the hands of NHC XIII and NHC II to be very similar.

88 References to the page number in NHC follows the order reconstructed and established in the Facsimiles. 


\begin{tabular}{llll}
\hline Scribes & NHC & Graphical styles & Proposed dating \\
\hline 1 & I, pp. A-43, I. 24; 51-138 & BM & $4^{\text {th }}$ cent., $2^{\text {nd }}$ half \\
2 & I, pp. 43, I. 25-50, I. 18; XI, pp. 1-44 & Severe style $>$ SOM & $4^{\text {th }}$ cent., end \\
3 & II, pp. 1-46; 47, I. 8-145 & BM & $4^{\text {th }}$ cent., $2^{\text {nd }}$ half \\
4 & II, p. 47, II. 1-8 & BM & $4^{\text {th }}$ cent., $2^{\text {nd }}$ half \\
5 & III & AM & $4^{\text {th }}$ cent., $1^{\text {st }}$ half \\
6 & IV & AM & $4^{\text {th }}$ cent., $1^{\text {st }}$ half \\
7 & V & AM & $4^{\text {th }}$ cent., $1^{\text {st }}$ half \\
8 & VI & AM & $4^{\text {th }}$ cent., $1^{\text {st }}$ half \\
9 & VII; XI, pp. 45-72 & AM + BM & $4^{\text {th }}$ cent., $2^{\text {nd }}$ half \\
10 & VIII & AM & $4^{\text {th }}$ cent., $1^{\text {st }}$ half \\
11 & IX & AM & $4^{\text {th }}$ cent., $1^{\text {st }}$ half \\
12 & X & BM & $4^{\text {th }}$ cent., end \\
13 & XII & BM & $4^{\text {th }}$ cent., end \\
14 & XIII & BM + AM & $4^{\text {th }}$ cent., early \\
\hline
\end{tabular}

Tab. 2: Scribes and styles in NHC

$\mathrm{BM}=$ Biblical majuscule; $\mathrm{AM}=$ Alexandrian majuscule; $\mathrm{SOM}=$ sloping ogival majuscule.

\begin{tabular}{lllll}
\hline NHC & Gatherings & Dimensions W $\times$ H & Size $(\mathrm{mm})$ & Proportion \\
\hline I & 3 & $144 \times 300$ & 444 & 0,48 \\
II & 1 & $158 \times 284$ & 442 & 0,55 \\
III & 1 & $157 \times 257$ & 414 & 0,61 \\
IV & 1 & $132 \times 233$ & 365 & 0,56 \\
V & 1 & $133 \times 240$ & 373 & 0,55 \\
VI & 1 & $150 \times 280$ & 430 & 0,53 \\
VII & 1 & $175 \times 290$ & 465 & 0,60 \\
VIII & 1 & {$[150 \times 242]$} & 392 & 0,62 \\
IX & 1 & $152 \times 263$ & 415 & 0,57 \\
X & 1 & $122 \times 260$ & 382 & 0,47 \\
XI & 1 & $143 \times 282$ & 425 & 0,50 \\
XII & 1 & {$[190 \times 260]$} & 450 & 0,73 \\
XIII & 1 & $138 \times 272$ & 410 & 0,50 \\
\hline
\end{tabular}

Tab. 3: Main codicological features of NHC. 